\title{
Çocuklardaki çölyak hastalığının annelerin yaşam kalitesi ve depresyon düzeylerine etkisi
}

\author{
Effect of celiac disease in children on the quality of life and depression levels of mothers
}

\author{
(D) Nergiz SEVINÇ ${ }^{1}$ (D) Ahmet ÖZTÜRK'1 (D) Eylem SEVINÇ² \\ Erciyes Üniversitesi Tıp Fakültesi, 'Halk Sağlığı Anabilim Dalı, Kayseri \\ Kayseri Eğitim ve Araştırma Hastanesi, ${ }^{2}$ Çocuk Gastroenterolojisi Kliniği, Kayseri
}

Giriş ve Amaç: çölyak hastalı̆ı olan çocukların sürekli olarak glutensiz diyete uyma zorun/uluğu çocukla birlikte ailesine de psikososyal bir yük getirmekte ve özellikle çocuğun birincil bakımından sorumlu annelerin yaşam kalitesini ve psikososyal durumlarını olumsuz etkileyebilmektedir. Bu çalışmada çölyak hastalığı olan çocukların annelerinin, kontrol grubundaki çocukların anneleri ile karşılaştııılarak, yaşam kalitesinin ve depresyon düzeylerinin incelenmesi amaçlanmıştır. Gereç ve Yöntem: Çalışma Erciyes Üniversitesi Çocuk Sağlığı ve Hastalıkları Anabilim Dalı Gastroenteroloji Polikliniğinde 1 Temmuz-31 Aralık 2015 tarihleri arasında yapılmıştır. Çalışma grubuna; 93 çölyak hastalığı olan çocuğun annesi ile 93 sağlam çocuğun annesi olmak üzere toplam 186 anne alınmıştır. Çalışmaya katılan tüm annelerden sözlü onam alınarak, sosyodemografik veri formu, yaşam kalitesi ölçeği (SF-36) ve Beck Depresyon Ölçeği yüz yüze görüşme tekniği ile uygulanmıştır. Verilerin değerlendirilmesinde SPSS paket programı kullanılmıştır. İstatistiksel analizlerde $p<0.05$ değerleri anlamlı kabul edilmiştir. Bulgular: Çölyak hastalığı olan çocukların annelerinde kontrol grubundaki çocukların annelerine göre yaşam kalitesi puanları daha düşük bulunmuştur (Sırasıyla genel sağlık (32 ve 44), fiziksel fonksiyonellik (50 ve 80), fiziksel rol güçlügü (50 ve 100), mental sağlık (48 ve 72), enerji (35 ve 60), emosyonel sağlık (33.33 ve 100), bedensel ağrı (30 ve 70) ve sosyal fonksiyonellik (50 ve 62.50). Özellikle eğitim düzeyi düşük olan, 4 ve üzeri çocuk sahibi olan, ekonomik durumu kötü olan ve herhangi bir işte çalışmayan çölyaklı çocuk annelerinde yaşam kalitesi puanları daha düşük bulunmuştur. Beck Depresyon Ölçeğine göre yapılan değerlendirmelerde de; çölyaklı çocuk annelerinde depresif belirti görülme oranı (\%69.9) kontrol grubundaki annelere göre (\%14.0) anlamlı derecede yüksek bulunmuştur. Yapılan ileri analizlerde; 41 yaş ve üzerinde olan, 4 ve üzeri çocuk sahibi olan, ekonomik durumu kötü olan ve köy ve kasabalarda yaşayan annelerde depresif belirti oranları daha fazla bulunmuştur. Sonuç: Annelerin, kronik hastalığı olan çocuğu ile uğraşırken yaşam kalitelerinin ve beden-ruh sağlıklarının olumsuz yönde etkilendiği tespit edilmiştir. Çölyak hastalığı olan bir çocuk tespit edildiğinde, annelerinin de yaşam kalitelerinin korunması ya da ruhsal sıkıntılarla karşılaşmalarının önlenmesi açısından takip edilmesinin ve destek olunmasının yararlı olacağı düşünülmektedir.

Anahtar kelimeler: Çölyak hastalığı, anne, yaşam kalitesi, depresyon

\section{GíRiş}

Çölyak hastalığı (ÇH) genetik olarak yatkın kişilerde buğday, arpa, çavdar gibi tahıllarda bulunan glutene karşı gelişen intestina enflamasyonla karakterize olan kronik bir hastalıktır (1).

Iletişim: Eylem SEVINÇ

Kayseri Eğitim ve Araştırma Hastanesi, Çocuk Gastroenterolojisi Kliniği, Kayseri

E-mail: dr.eylemsevinc@gmail.com
Background and Aims: The compulsory obligation to follow a gluten-free diet in children with celiac disease brings a psychosocial burden both to the child and the family. It has negative effects on the quality of life and psychosocial status of the mother who is primarily responsible for the child's care. We compared the quality of life and depression levels between mothers of children with celiac disease and controls. Materials and Methods: The study was performed at the gastroenterology polyclinic of Erciyes University Pediatric Department between July 1, 2015, and December 31, 2015. Mothers of 93 children with celiac disease and mothers of 93 healthy children (a total of 186 mothers) were included in the study. Verbal affirmation was obtained from all the participants. A sociodemographic questionnaire, quality of life scale (short form-36), and Beck Depression Inventory were administered through a face-to-face interview. The Statistical Package for Social Sciences program was used for evaluating data. A p value of $<0.05$ was accepted as significant. Results: The quality of life scores of mothers to children with celiac disease were lower compared to the control group (general health [32 vs 44], physical functioning [50 vs 80], physical role limitations [50 vs 100], mental health [48 vs 72], energy [35 vs $60]$, emotional health [33.33 vs 100], bodily pain [30 vs 70], and social functioning [50 vs 62.50]). Particularly, in mothers of children with celiac disease who had a low educational status or economic situation, had 4 or more children, and were unemployed, the quality-of-life scores were lower than others. According to the Beck Depression Inventory, depression symptom rates were higher in the mothers of children with celiac disease (69.9\%) compared to the control group (14.0\%). With advanced analysis, higher depression symptom rates were noted in mothers older than 41 years, having 4 or more children, being in a lower economic status, and living in a village or small town. Conclusions: The quality of life and physical-mental health are affected negatively while mothers struggle with their children's chronic disease. When a child with celiac disease is identified, it would be beneficial to follow up and support the mother to maintain her quality of life and prevent mental distress.

Key words: Celiac disease, mother, life quality, depression

ÇH'nın tedavisi, ömür boyu sürecek glutensiz diyettir. Bu tedaviye sıkı bir şekilde uyulması hastalı̆ın prognozu açısından önemlidir (2,3). Ailede kronik hastalığa sahip bireyin olması tüm aile fertlerinin yaşam kalitesini ve ruhsal duru- 
munu etkilemektedir. Dünya Sağlık Örgütü'ne (DSÖ) göre yaşam kalitesi; bireylerin yaşadıkları kültür ve değerler sistemi içerisinde amaçları, beklentileri, ilgi alanları ve yaşam standartları doğrultusunda hayattaki pozisyonlarını nasıl algıladıklarıdır. Kronik bir hastalık olan $\mathrm{C} H$, glutensiz diyete uyum, yüksek gıda maliyeti, okulda, sosyal alanlarda yemek problemleri ve bu yemeklerin hazırlanması ve tedaviye uyum korkusu gibi sebeplerden dolayı psikolojik yönden anksiyete ve depresyon gibi olumsuz etki yaratabilir $(4,5)$.

Hastalığın seyrinde ÇH tanısı almış çocukların annelerinde de yaşam kalitesinde değişikliklerle birlikte depresyon vb. ruhsal sorunların da çıkabileceği bildirilmiştir (6). Günümüzde bireylerin yaşam kalitesi ve depresyonun düzeyini değerlendiren çeşitli testler geliştirilmiştir $(7,8)$. Çalışmamızda, ÇH olan çocukların annelerinin yaşam kalitesi ve depresyon düzeylerinin kontrol grubuyla karşılaştırılarak incelenmesi amaçlanmıştır.

\section{GEREÇ ve YÖNTEM}

Bu kesitsel araştırmaya, Erciyes Üniversitesi Tıp Fakültesi Çocuk Gastroenteroloji polikliniğinde 1 Temmuz-31 AraIık 2015 tarihleri arasında en az 3 aydan beri takip edilen 93 çölyaklı çocuğun annesi dahil edilmiştir. Kontrol grubu olarak sağlam çocuk polikliniğine çeşitli sebeplerle başvuran kronik hastalığı olmayan 93 çocuğun annesi dahil edildi.

Çalışmaya katılan tüm annelere toplamda 36 çoktan seçmeli sorudan oluşan ve fiziksel fonksiyonellik (FF) (sağlık sorunları nedeniyle fiziksel aktivitede kısıllanma), fiziksel rol güçlüğü (FRG) (sağlık sorunları nedeniyle günlük yaşam aktivitelerinde kısıtlanma), bedensel ağrı (BA), genel sağlık (GS) (kişinin genel olarak sağlığını değerlendirmesi), canlılık (CA), mental sağlık (MS), sosyal fonksiyonellik (SF) ve emosyonel sağlık (ES) sorunları nedeniyle günlük yaşam aktivitelerinde kısıtlanma boyutlarını sorgulayan alt ölçek puanları 0-100 arasında değişen Short Form-36 anketi (SF-36) ile 21 sorudan oluşan ve her soru 0 ile 3 arasında puan verilerek değerlendirilen Beck Depresyon Ölçeği (BDÖ) uygulandı. BDÖ'den alınan puanlara göre depresyon düzeyleri: 0-10 puan depresyon yok; 11-16 puan hafif ruhsal sıkınt।; 17-20 puan sınırda klinik depresyon; 21-30 orta düzeyde depresyon, 31-40 ciddi depresyon, 41 ve üzeri çok ciddi depresyon şeklinde yorumlandı. Veriler SPSS 22.0 paket programında değerlendirildi. Nicel verilerin normal dağılım uygunluğuna Shapiro-Wilk Testi ile bakıımıştır. Normal dağılıma uyan veriler ortalama ve standart sapma olarak gösterilmiş ve t-testi ile karşılaştııımıştır. Normal dağılıma uymayan değişkenler ortanca, min-maks. ve yüzde dağlımla özetlendi. Normal dağılıma uymayan veriler Kruskal Wallis (Post hoc, Dunn's test), ve Mann Whitney U testi ile karşılaştırılmışıı. Çalışma için 2015 yılında Erciyes Üniversitesi Tıp Fakültesi etik kurulundan (karar no: 2015/255) onay alındı.

\section{BULGULAR}

Araştırmaya katılan annelerin yaş ortalaması 38.0 yı idi. Annelerin \%46.2'sinin ilkokul mezunu, \%51.1'inin ekonomik durumunun orta düzeyde olduğu, \%58.1'nin il merkezinde ikamet etmekte olduğu saptanmıştır. Araştırmaya katılan annelerin \%13.4'ünde herhangi bir kronik hastalık bulunmakta olup \%12.9'unun sürekli bir ilaç kullanmakta olduğu saptanmıştır.

Çalışma grubundaki annelerle kontrol grubundaki annelerin SF-36 boyutları olan genel sağlık, fiziksel fonksiyonellik, fiziksel rol güçlüğü, mental sağlık, enerji, emosyonel sağlık, bedensel ağrı ve sosyal fonksiyonellik arasında istatistiksel açıdan anlamlı farklılık bulunmuştur $(p<0.001)$. Çalışma grubunda SF-36 puanları tüm boyutlarda daha düşük saptanmıştır (Tablo 1). Çalışma grubundaki sahip

\section{Tablo 1. Araştırmaya katılan annelerin SF-36 boyutlarından aldıkları puanlar}

\begin{tabular}{|lcccc|}
\hline SF-36 Boyutları & $\begin{array}{c}\text { Çölyak Grubu } \\
\text { Ortanca } \\
\text { (Min.-Maks.) }\end{array}$ & $\begin{array}{c}\text { Kontrol Grubu } \\
\text { Ortanca } \\
\text { (Min.-Maks.) }\end{array}$ & Z & p \\
\hline Genel sağlık & $32(0-56)$ & $44(8-80)$ & 5.88 & $<0.001$ \\
\hline Fiziksel fonksiyonellik & $50(0-100)$ & $80(0-100)$ & 5.69 & $<0.001$ \\
\hline Fiziksel rol güçlüğü & $50(0-100)$ & $100(0-100)$ & 5.56 & $<0.001$ \\
\hline Mental sağlık & $48(12-88)$ & $72(24-100)$ & 7.43 & $<0.001$ \\
\hline Enerji & $35(0-80)$ & $60(5-95)$ & 7.33 & $<0.001$ \\
\hline Emosyonel sağlık & $33.3(0-100)$ & $100(0-100)$ & 5.34 & $<0.001$ \\
\hline Bedensel ağrı & $30(0-90)$ & $70(10-90)$ & 6.81 & $<0.001$ \\
\hline Sosyal fonksiyonellik & $50(0-100)$ & $62.5(12-100)$ & 5.73 & $<0.001$
\end{tabular}


Tablo 2. Araştırmaya katılan annelerin Beck Depresyon Ölçeği puan ortancalarına göre karşılaştırılması

\begin{tabular}{|lcc|}
\hline Gruplar & $\mathbf{n}$ & $\begin{array}{c}\text { BDÖ Puanı } \\
\text { Ortanca (Min.-Maks.) }\end{array}$ \\
\hline Çölyak grubu & 93 & $21(0-50)$ \\
\hline Kontrol grubu & 93 & $8(0-14)$ \\
\hline z=7.70, p<0.001 & \\
\hline BDÖ: Beck depresyon ölçeği & \\
\hline
\end{tabular}

olunan çocuk sayısı ile SF-36 boyut puanları arasında yapılan karşılaştırmada; dört ve üzeri çocuk sahibi olan annelerin tüm boyutlarda aldıkları puanlar, daha az çocuk sahibi olanlara göre daha düşük olarak bulunmuştur. ÇH olan çocukların annelerinin eğitim düzeyleriyle SF-36 boyut puanları arasında yapılan karşılaştırmada; genel sağlık, mental sağlık, enerji ve bedensel ağrı boyut puanlarının üniversite mezunu annelerde daha yüksek olduğu görülmüştür. Annelerin ekonomik durumuna göre SF-36 boyut puanlarıyla yapılan karşılaştırmada; fiziksel rol güçlüğü, enerji, emosyonel sağlık, bedensel ağrı ve mental sağlık boyut puanlarının ekonomik durumu iyi olanlarda daha yüksek olduğu saptandı. Annelerin yaşadıkları yer ile yaşam kalite puanları arasında yapılan karşılaştırmada herhangi bir farklılık bulunmadı.

Çalışma grubundaki annelerde BDÖ puanı kontrol grubundaki annelere göre çok daha yüksek olduğu bulundu (Tablo 2). Araştırmaya katılan annelerde BDÖ puanları- nın ayrıntılı sınıflamasına göre yapılan dağılım Tablo 3'te gösterildi. Çalışma ve kontrol gruplarının BDÖ puanının kesim noktası 17 alınarak yapılan karşılaştırmada çalışma grubundaki annelerin \%69.9'unun, kontrol grubundaki annelerin ise \%14'ünüğn 17 ve üzeri puan aldığı saptandı (Tablo 4). Ekonomik durumu iyi olan (\%5.3) ve çölyakIı çocuğu 9 yaş ve altında (\%50.0) olanlarda depresyon oranları daha düşük bulundu. Araştırmaya katılan annelerin, eğitim durumları, yaş grupları, yaşadıkları yer, çocuk sayıları ve çölyak hastalık süreleri ile depresyon durumları arasında anlamlı farklılık bulunmadı ( $p>0.05$ ).

\section{TARTIŞMA}

Bu çalışmada çölyaklı çocuk annelerinin SF-36 ölçeğine göre yaşam kalitesinden aldıkları puanlar kontrol grubuna göre düşük tespit edilirken BDÖ'ne göre çölyaklı çocuk annelerinde depresif belirti görülme oranının kontrol grubundaki annelere göre çok daha yüksek olduğunu saptanmıştır.

Kronik hastalığı olan çocukların annelerinde yaşam kalitesi değerlendirilmesi konusunda yapılmış çalışmalar nörolojik problemleri olan çocuklar üzerinde yoğunlaşmış olup çölyak hastalığı olan çocukların annelerinde yapıımış çok az sayıda çalışma bulunmaktadır $(9,10)$. Lorenzo ve ark.nın Brezilya'da Joana de Gusmao çocuk hastanesinde yaptığı bir çalışmada, çölyak hastalığı olan çocukların ebeveynlerinde yaşam kalitesi puanları sağlam çocukların ebeveynlerine göre anlamlı ölçüde düşük olarak bildirmiş

Tablo 3. Beck Depresyon Ölçeğinin puan aralıklarına göre dağılımı

\begin{tabular}{|lcccc} 
& \multicolumn{2}{c}{ Çalışma Grubu } & \multicolumn{2}{c}{ Kontrol Grubu } \\
\hline Normal & Sayı & $\%$ & Sayı & $\%$ \\
\hline Hafif ruhsal sıkıntı & 11 & 11.8 & 62 & 66.7 \\
\hline Sınırda klinik depresyon & 17 & 18.2 & 18 & 19.4 \\
\hline Orta depresyon & 14 & 15.1 & 4 & 4.3 \\
\hline Ciddi depresyon & 29 & 31.2 & 8 & 8.5 \\
\hline Çok ciddi depresyon & 17 & 18.3 & 0 & 1.1 \\
\hline $\mathbf{x}^{2}=\mathbf{7 0 . 4}, \mathbf{p}<\mathbf{0 . 0 0 1}$ & 5 & 5.4 & & 0.0 \\
\hline
\end{tabular}

Tablo 4. Çalışma ve kontrol gruplarının depresyon durumuna göre karşılaştırılması

\begin{tabular}{|lcccccc}
\hline BDÖ Puan & \multicolumn{2}{c}{ Çalışma Grubu } & \multicolumn{2}{c}{ Kontrol Grubu } & \multicolumn{2}{c}{ Toplam } \\
& Sayı & $\%$ & Sayı & $\%$ & 86.0 & 108 \\
\hline 16 puan ve altı (Normal) & 28 & 30.1 & 80 & 14.0 & 78 & \\
\hline 17 puan ve üzeri (Klinik depresyon) & 65 & 69.9 & 13 & 14.0 &
\end{tabular}

BDÖ: Beck depresyon ölçeği 
olup sonuçları bizim araştırmamızın bulgularını desteklemektedir (6). Bizim çalışmamızın bulgularından farklı olarak, Kara ve ark.nın 40 çölyaklı çocuğun annelerinde yaptığı çalışmada ise, kontrol grubu ile yaşam kalitesi puanları açısından anlamlı fark bulunmadığı görülmüştür (11). Bu durumun muhtemel nedeni çalışmaya alınan vaka sayııının az olmasından kaynaklanmış olabilir.

Çölyak hastalığı, ömür boyu sıkı glutensiz diyet gerektiren ve bu diyetle beraber semptomları iyileşen ve komplikasyonları önlenebilen kronik bir hastalıktır (12). Glutensiz diyete uyumun çocuklarda daha zor olması muhtemeldir ve bu durum anneler için fazladan bir uğraş gerektirebileceğinden anneleri psikososyal yönden olumsuz etkileyebilir $(6,13)$. Bulduğumuz sonuçlar da çalışma grubundaki annelerin psikolojik yönden olumsuz etkilendiğini göstermiştir. Epifanio ve ark.nın çölyak hastalığı olan çocukların annelerinde yaptıkları bir çalışmada stres düzeyinin sağlam çocuk annelerine göre daha yüksek olduğu sonucu bizim çalışmamızın sonuçlarıyla uyumludur (14).

Toros ve ark.nın, kronik hastalığı olan çocukların ebeveynlerinde yaptığı bir çalışmada eğitim seviyesi ile depresyon düzeyleri arasında negatif korelasyon bulunmuştur (15). Çalışmamızda annelerin çocuklarının yaş gruplarıyla BDÖ puanları arasında yapılan karşılaştırmada hem kontrol grubunda hem de çalışma grubunda, depresif belirtilerin en fazla 15 yaş ve üzeri çocuk annelerinde görüldüğü saptandı. Bu durum çocukların bu yaş grubunda kendi benlik algılarının oluşması, otoriteye karşı olma, söz dinlememe ve glutensiz diyeti reddetme gibi sebeplerden dolayı anneyi daha fazla strese maruz bırakmasından kaynaklanması muhtemeldir.

\section{KAYNAKLAR}

1. Sevinç $E$, Sevinç $N$, Sezgin $G$, et al. Çölyaklı çocuk hastalarımızın klinik değerlendirilmesi. Akademik Gastroenteroloji Dergisi 2015; $14: 1-4$.

2. Hill ID, Dirks MH, Liptak GS, et al; North American Society for Pediatric Gastroenterology, Hepatology and Nutrition. Guideline for the diagnosis and treatment of celiac disease in children: recommendations of the North American Society for Pediatric Gastroenterology, Hepatology and Nutrition. J Pediatr Gastroenterol Nutr 2005;40:119.

3. Gujral N, Freeman HJ, Thomson AB. Celiac disease: Prevalence, diagnosis, pathogenesis and treatment. World J Gastroenterol 2012;18:6036-59.

4. Casellas F, Rodrigo L, Lucendo A, J et al. Benefit on health-related quality of life of adherence to gluten-free diet in adult patients with celiac disease. Rev Esp Enferm Dig 2015;107:196-201.

5. Durualp E, Kara FN, Yılmaz V, Alabeyoğlu K. Kronik hastalığı olan ve olmayan çocukların ve ebeveynlerinin görüşlerine göre yaşam kalitelerinin karşılaştırılması. Ankara Üniversitesi Tıp Fakültesi Mecmuası 2010;63:55-63.
Olsson ve ark.nın yaptıkları bir çalışmada; düşük sosyoekonomik koşulların, çocuklarında kronik hastalık olan ebeveynlerde depresif belirtileri arttırdığı bildirilmiştir (16). Olssonve ark.nın bildirdikleri sonuçlarla uyumlu olarak bizim araştırmamızda da çalışma grubunda ekonomik durumu kötü ve orta olan annelerde depresyon puanının yüksek olduğu saptanmıştır. Ailenin gelir düzeyinin düşmesi anneleri daha fazla stres altında bırakabilir. Annelerin ekonomik yönden daha fazla stres altında olmaları, glutensiz diyet ürünlerini alım gücünün azlığı ve ailenin ek masrafları karşılamada zorlanmalarından kaynaklandığını düşünmekteyiz.

Çalışmamızda en büyük kısıtlama, sonuçlarımızı kıyaslayabileceğimiz ÇH olan çocukların ebeveynlerinde yaşam kalitesini ve depresyon durumunu değerlendiren az sayıda çalışma olmasıdır.

Sonuç olarak ÇH olan bir çocuk tespit edildiğinde, annelerinin de yaşam kalitelerinin korunması ya da ruhsal sıkıntılarla karşılaşmalarının önlenmesi açısından sağlık personeli tarafından takip edilmelerini önerebiliriz. Özellikle bunların içerisinde; çalışmamızda daha riskli olarak tespit ettiğimiz, ekonomik durumu orta-kötü olan, çocuk sayısı fazla olan, eğitim seviyesi düşük olan ve adölesan dönemde çocuğu bulunan annelere karşı daha dikkatli olunmalıdır. Bu kapsamda; annelerin yaşam kalitesini ve depresyon durumlarını etkileyen başka durumların araştırılmasının ve annelerin yaşam kalitesini ve depresif durumlarını iyileştirmek ve çocuklarına daha iyi bakım verebilmeleri için nasıl destek verilebileceği konusunda daha fazla çalışmanın yapılmasının, danışmanlık ve eğitim hizmetlerinin artııımasının yararlı olabileceği düşünülmektedir.

6. de Lorenzo CM, Xikota JC, Wayhs MC, et al. Evaluation of the quality of life of children with celiac disease and their parents: a case-control study. Qual Life Res 2012;21:77-85.

7. Beck AT, Steer RA, Carbin MG. Psychometric properties of the Beck Depression Inventory: Twenty-five years of evaluation. Clin Psychol Rev 1988;8:77-100.

8. Aydemir Ö. Konsültasyon-liyezon psikiyatrisinde yaşam kalitesi ölçümü: Kısa form-36 (SF-36). Psikiyatri Psikoloji Psikofarmakoloji (3P) Dergisi 1999;7:14-22.

9. Cogulu O, Ozkinay F, Gunduz C, et al. Celiac disease in children with Down syndrome: importance of follow-up and serologic screening. Pediatr Int 2003;45:395-9.

10. Fazlıŏlu K, Hocaoğlu Ç, Sönmez FM. Çocukluk çağı epilepsisinin aileye etkisi. Psikiyatride Güncel Yaklaşımlar 2010;2:190-205.

11. Kara A. Çölyaklı çocuk ve ergenlerde psikopatoloji ile hasta ve annelerinin yaşam kalitelerinin değerlendirilmesi. Tıpta Uzmanlık Tezi. Erciyes Üniversitesi Tıp Fakültesi Çocuk Psikiyatrisi Anabilim Dalı. Kayseri 2015. 
12. Çoşkun BD, Sevinc E, İpek, et al. Erişkin çölyaklı hastalarımızın klinik değerlendirilmesi. Endoscopy Gastrointestinal 2015;23:40-3.

13. Sevinc E, Cetin F, Coskun BD. Psychopathology, quality of life, and related factors in children with celiac disease. J Pediatr (Rio J) 2017;93:267-73.

14. Epifanio MS, Genna V, Vitello MG, et al. Parenting stress and impact of illness in parents of children with coeliac disease. Pediatr Rep 2013;5:e19.
15. Toros F, Tot Ş, Düzovalı Ö. Kronik hastalığı olan çocuklar, anne ve babalarındaki depresyon ve anksiyete düzeyleri. Klinik Psikiyatri Dergisi 2002;5:240-7.

16. Olsson MB, Hwang CP. Depression in mothers and fathers of children with intellectual disability. J Intellect Disabil Res 2001;45:53543 